\title{
Study on the Isothermal-Forging of the wheel rim of Aluminum alloy
}

\author{
KANG Feng $^{1, a,}$ ZHAO Zude $^{1, b}$, CHEN Qiang ${ }^{1, c}$, HUANG Shuhai ${ }^{1, d}$ \\ HU Chuankai ${ }^{1, e}$ \\ ${ }^{1}$ Southwest Technique and Engineering Institute, Chongqing 400039, PR China \\ atiannakaff@163.com, ${ }^{b}$ cqzzd@163.com, ${ }^{c} 2009$,henqian@163.com, ${ }^{\mathrm{d}}$ hsh82@163.com, \\ ekaizihu@163.com
}

Keywords: vehicle, isothermal-forging, wheel rim, forging.

Abstract. With the development of the lightweight trend, the wheel rim of automobile is always made of aluminum alloy, which put forward higher requirements to the capability of the rim. Because of its big size, complex figure, and material with hard deformation, the wheel rim always take on cracks during the traditional forging. This paper study on the Isothermal-Forging, the blank and the mould can always keep at the same temperature during forging, and also with a constant strain rate, with which it can avoid the temperature decrease and the effect of cold mould during forging. On the other hand, with prefabricated pipe, the perforation extrusion is used to obtain the required deformation through multiple backward extrusion. This process greatly reduced the forming force, and also overcome the defect of crack at the inner rim.

\section{Introduction}

Hubs and rims of vehicles are important loading-bearing structural components with complicated working conditions and they work under environments with high strength, complicated stress and large temperature difference on the long-term basis, therefore, may parts of their structures may suffer from fatigue rupture, on the other hand, with the development of light weight trend for vehicles, most wheel rims are made of aluminum alloy, which demands high performance of wheel rims. So materials are mostly high strength aluminum alloy, materials potential are dug as far as possible for manufacturing process aspects to ensure continuity of basic flow line of components, and save materials used on the basis of guarantee on performance of components ${ }^{[1} \sim^{2]}$. Due to general characters of wheel rims-large size, complicated shape and poor materials forming property, serious cracks such as cracks always happen in routine forging process, therefore isothermal-forging process, which makes preform bodies and moulds constantly under the same temperature and take shape at the constant strain rate in the forming process and avoid reduced temperature and mould cooling effects in the forming process, low machinable plasticity, narrow thermoforming temperature range, large heat conductivity coefficient and forming of complicated components with low machinability, is used in the thesis $\left.{ }^{[3} \sim 4\right]$.

\section{Process analysis}

Fig. 1 is a wheel rim of an automobile made of 7A04 aluminum alloy materials, with relatively big structure size, $508 \mathrm{~mm}$ bottom diameter, $600 \mathrm{~mm}$ mouth diameter and only $12 \mathrm{~mm}$ thick walls. Forging design is as shown in Fig. 2. The process design adopts $520 \mathrm{~mm}$ diameter bar to have multi-steps extrusion for performing, and finally upside down edges to forge the mouth. Due to large deformation and forming load of the component and 7A04 extra super duralumin alloy's difficulty in taking shape, forming force should be reduced as far as possible; at the same time, attention should be paid to prevent cracks appearing on the bottom of extruded stock. 


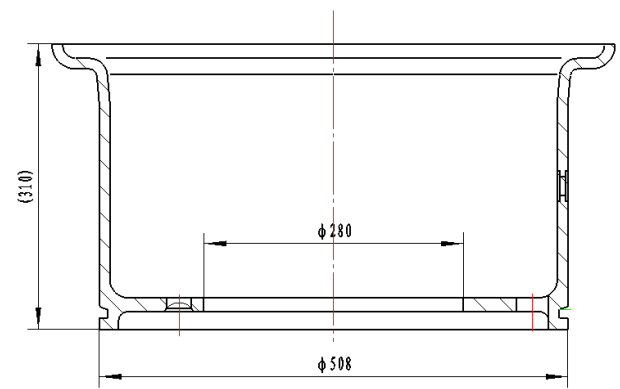

Fig.1 Wheel rim of automobile

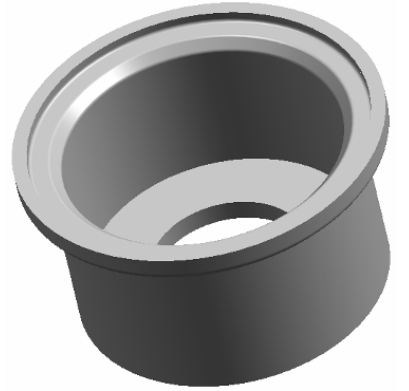

Fig.2 Rim forging

Original process of the component uses traditional heat extrusion forming, because of large size of components, rapid heat dissipation in forming process, relatively sensitivity of 7A04 to temperature changes, and due to too large transformation, too quick temperature drop in the trial-manufacture, defaults are found in detection on the work piece, and extrusion cracks are found at bottom of the work piece by wire-electrode cutting on the work piece, as shown in Fig. 3.

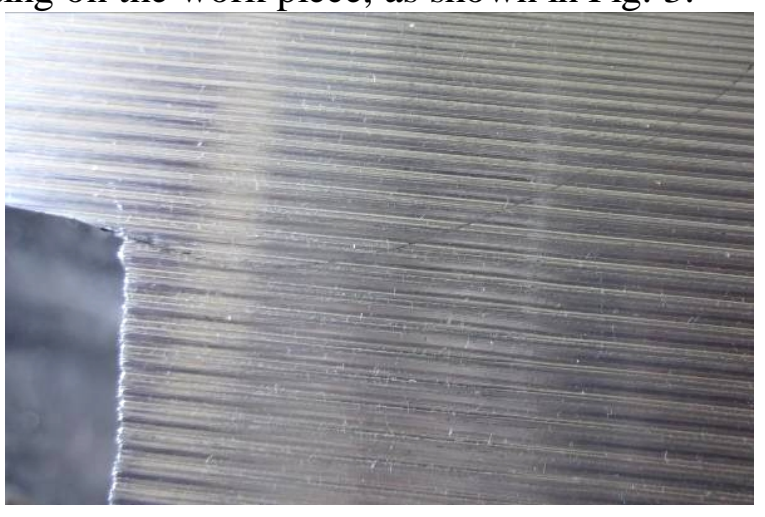

Fig.3 The crack in the rim

\section{Process design and test}

Due to wheel rims as large-scale hollow rotational parts and $280 \mathrm{~mm}$ diameter through-hole in the component center, to reduce forming force, $\varphi 300 \mathrm{~mm}$ bars are used to upset into $\varphi 520 \mathrm{~mm}$ round cake preform bodies, by backward extrusion, punching slugs, turning the bottom, pipe preform bodies of $520 \mathrm{~mm}$ outer diameter and 390 inner diameter are prepared; and then, use pipe preform bodies to repeatedly conduct backward extrusion, sloe press, oral area turnup and compression. The process (Fig. 4), which is capable of reducing forming force and reaching deformation required by components by many forming steps, is mainly used in forming of pipe preform bodies.

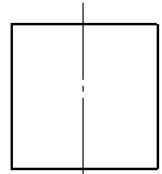

下料

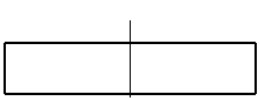

筑销

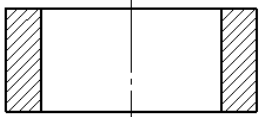

多次反挤庄

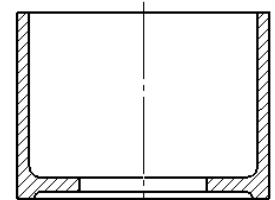

反挤瓜十压底

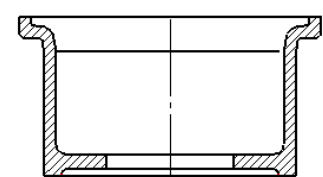

扩口翻边

Fig.4 The process of the rim 


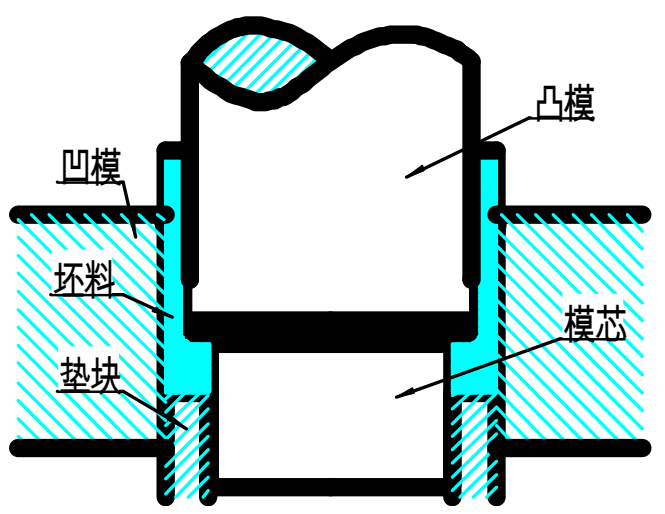

Fig.5 The perforation extrusion process

Fig. 5 is isothermal extrusion process for rim perforation. Transformation metal at bottom of terrace dies is located at strong three-dimensional compressive stress, and moulds and preform bodies are at the same heat preservation conditions, which reach necessary conditions f or isothermal forming; due to large scale contact area reduction to preform bodies, extrusion force in the whole forming process is largely reduced and stress on moulds is effectively improved ${ }^{[5]}$.

To avoid cracks in rim forming, isothermal forming process is used: preform bodies are heated to $450^{\circ} \mathrm{C}$; moulds are heated to $420^{\circ} \mathrm{C}$; heat preservation is reserved for 2-3 hours; lubrication uses oil-based graphite and equipment adopts $1600 \mathrm{~T}$ four-column oil hydraulic press. As for temperature control which is critical to forming, two-circuit feedback and cascade connection temperature control system is equipped for the whole process, and in the forming process, moulds and preform bodies are constantly under heat preservation state, as shown in Fig. 6.

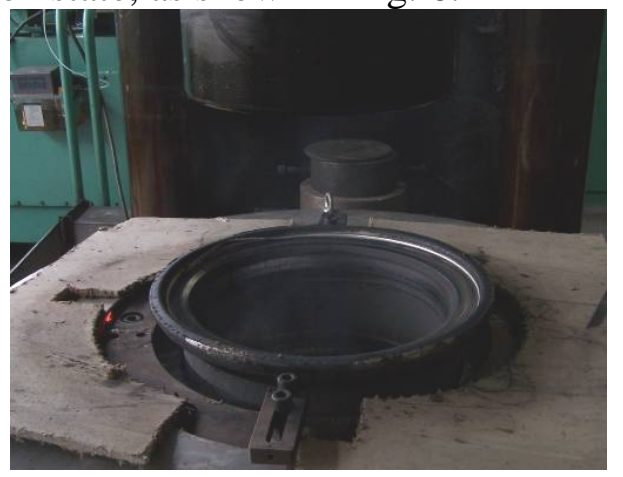

Fig. 6 The process of Isothermal-Forging

Fig. 7 is final forging finished products for isothermal forming of rims. After using perforation and isothermal extrusion process, rim forging pieces have full mold filing after backward extrusion, sole press and turnup at oral area for many times, no extrusion cracks by conventional hot die forging appear at inner bottom and no cracks, enfolds and other cracks turn up at outer surface. Through analysis on microstructure of rim walls (Fig. 8), the structure has full recrystalization, and after large deformation crushing, its longitudinal structures have obvious directionality. After test, size and surface quality, etc. of forging pieces of rims fully satisfy technical requirements of products.
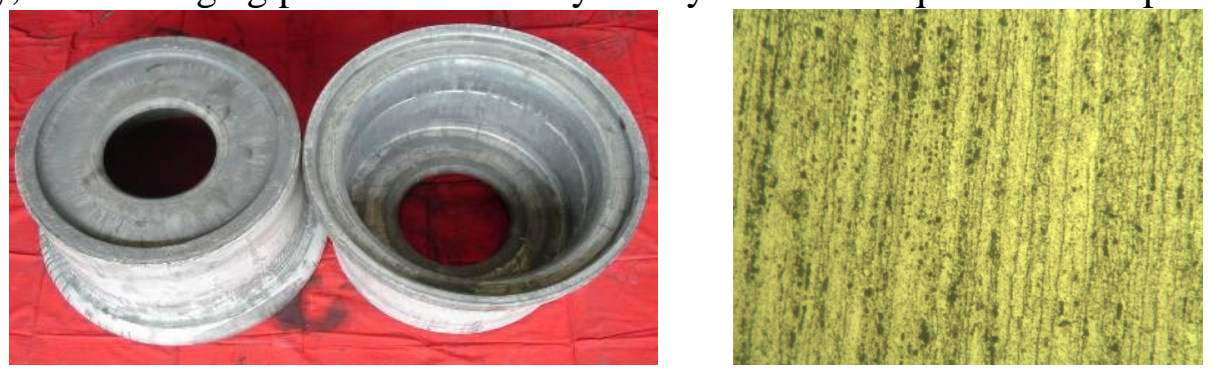

Fig.7 The forging of wheel rim

Fig.8 Microstructure on the rim side 


\section{Conclusion}

(1) During isothermal forming, moulds and preform bodies are always under the same temperature, so under the relatively low forming speed rate, resistance to deformation of metal is largely reduced, mobility of metal in die cavity is largely increased and recrystallization for inner structure of forging piece is full, which are beneficial to avoid all kinds of defects in forming process and obtain forging pieces with good structure performance.

(2) As for large scale rim type components, pipe preform bodies are prepared by repeated backward extrusion, and deformation required by components is reached by perforation and backward extrusion, sole press, turnup at oral area and compression, at the same time, forming force can be largely reduced to improve stress on moulds.

(3) After using perforation and isothermal extrusion process to conduct trial-manufacture, inner chamber of the bottom prepared has no extrusion cracks, no cracks, enfolds and other cracks turn up at outer surface. Through analysis on microstructure of rim walls, the inner structure has full recrystalization. Size and surface quality, etc. of forging pieces fully satisfy technical requirements of products.

\section{References}

[1]ZHANG Zhimin,WANG Qiang,LU Guang,YU Jianmi: Journal of Mechanical Engineering, Vol. 48-18(2012),p.56-59.

[2]CAO Junlmi.:Aluminum Fabrication Vol.23-4(2000),p.34-36.

[3]ZHANG Hongwei, NIU Zhanxian, WANG Xiuua:Light Alloy Fabrication Technology, Vol.34-5(2006),p.31-34.

[4]FU Jingsong, WANG Huachang, JIN Hao:Hot Working Technology Vol.37-21(2008),p.74-76.

[5] SHAN Debin, ZHANG Yanqiu, WANG Yong, et a1.:Trans Nonferrous Met Soc China Vol.6-S3(2006),p.1574-1579 